\title{
A national consensus on prevention of early-onset group B streptococcal infection in the newborn
}

A NATIONAL CONSENSUS STATEMENT ON THE PREVENTION of early-onset group B streptococcal (GBS) infections in the newborn was recently released by the Infectious Disease and Immunization Committee and the Fetus and Newborn Committee of the Canadian Paediatric Society in conjunction with the Maternal/ Fetal Medicine Committee of the Society of Obstetricians and Gynaecologists of Canada (1,2 and pages 251 to 256 in this issue of the Journal). This statement analyzes and summarizes the current state of knowledge about prevention of GBS infections and provides guidelines for management of pregnant woman and their newborns.

GBS continues to be a major source of sepsis in newborn infants who are infected before or during delivery. Prematurity, prolonged rupture of membranes, intrapartum fever and low socioeconomic status are among the risk factors of early-onset GBS disease. Of the various strategies attempted to reduce the incidence of disease (antimicrobial prophylaxis of the newborn, antepartum treatment of the colonized mother, passive immunization with immunoglobulin), only intrapartum chemoprophylaxis has been successful in decreasing the incidence of early-onset GBS disease (3). Identifying high risk pregnancies for intrapartum chemoprophylaxis has been problematic. Ideally, identification of high risk pregnancies at the time of delivery would permit selective chemoprophylaxis; however, the lack of a sufficiently sensitive rapid laboratory test to identify colonized woman in labour do not

All material presented in Pediatric Infectious Disease Notes has been reviewed and approved by the chairperson, Canadian Paediatric Society Board and representative members of the Canadian Pediatric Society Committee on Infectious Diseases and Immunization

Correspondence: Infectious Diseases and Immunization Committee, Canadian Paediatric Society, 401 Smyth Road. Ottawa, Ontario K1H 8L1. Telephone (613) 737-2728, Fax (613) $737-2794$ permit this option at this time. Two strategies have been widely recommended: universal screening of pregnant woman for GBS colonization with a single combined vaginal-anorectal swab for culture at 26 to 28 weeks and intrapartum chemoprophylaxis of GBS colonized women with risk factors (4); or intrapartum chemoprophylaxis of all women with risk factors without screening (5).

The Consensus Statement stresses the need for Canadian data to determine the best strategy for Canada. An urgent need was identified for additional Canadian research to determine GBS colonization rates in Canadian pregnant women, GBS disease rates, risk factors and outcome in newborn infants, as well as the cost and availability of laboratory diagnostic tests for GBS colonization and cost analyses of various intervention strategies. Pilot projects to assess these strategies and further research on other interventions including GBS vaccines were given high priority. Until these data become available, the consensus reached was that identification and management of women whose newborns may be at risk of early-onset GBS disease was acceptable by either universal screening at 26 to 28 weeks and intrapartum chemoprophylaxis of GBS-colonized women with risk factors, or no screening but intrapartum chemoprophylaxis of all women with risk factors. Available data favour the former approach; however, the financial cost of universal screening may be substantial.

Risk factors for which intrapartum chemoprophylaxis is recommended include: preterm labour (less than 37 weeks' gestation); term labour with maternal fever during labour (greater than $38^{\circ} \mathrm{C}$ orally); term labour with prolonged rupture of membranes (if labour is likely to continue beyond $18 \mathrm{~h}$ ); previous delivery of a newborn with GBs disease regardless of current GBS colonization status; and previously documented GBS bacteriuria (GBS bacteriuria should also be treated at the time it is identified). The antibiotic regimen of choice for intrapartum chemoprophylaxis is intravenous am- 
picillin or penicillin, or clindamycin in the penicillinallergic woman. Management of infants of mothers who received intrapartum prophylaxis must take into account their gestational age, sepsis evaluation and the adequacy of the chemoprophylaxis given. An algorithm for management of the newborn was suggested in the Consensus Statement.

With the publication of these long awaited guidelines, the challenge will be to generate the data that are required to determine the optimal strategy for Canada. This will require the commitment of both clinical and laboratory investigators, as well as provincial and federal research and health funding agencies. For health care providers, the challenge will be to ensure that one of the recommended strategies is implemented in every community. This will require close consultation and collaboration among obstetricians, pediatricians, family practitioners, nursing staff, clinical microbiologists and laboratory personnel. Although no intervention will prevent all GBS deaths, the time has come to implement a strategy that will reduce the impact of this deadly infection of newborns.

\section{REFERENCES}

1. Canadian Paediatric Society and the Society of Obstetricians and Gynaecologists of Canada. National consensus statement on the prevention of early-onset group B streptococcal infections in the newborn. Can J Paediatr. (In press)

2. Canadian Paediatric Society and the Society of Obstetricians and Gynaecologists of Canada. National consensus statement on the prevention of early-onset group B streptococcal infections in the newborn. J Soc Obstet Gynaecol Can 1994;16:2271-8.

3. Allen U, Navas L, King S. Effectiveness of intrapartum penicillin prophylaxis in preventing early-onset group B streptococcal infection: results of a meta-analysis. Can Med Assoc J 1993;149:1659-65.

4. Boyer KM, Gotoff SP. Prevention of early-onset neonatal group B streptococcal disease with selective intrapartum chemoprophylaxis. N Engl J Med 1986;314:1665-9.

5. Schuchat A, Oxtoby M, Cochi S, et al. Population-based risk factors for neonatal group B streptococcal disease: results of a cohort study in Metropolitan Atlanta. J Infect Dis 1990; 162:672-7.

Scott A Halperin MD

Departments of Pediatrics and Microbiology/Immunology

Dalhousie University and the IWK Children's Hospital

Halifax, Nova Scotia 


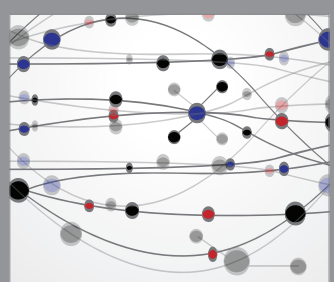

The Scientific World Journal
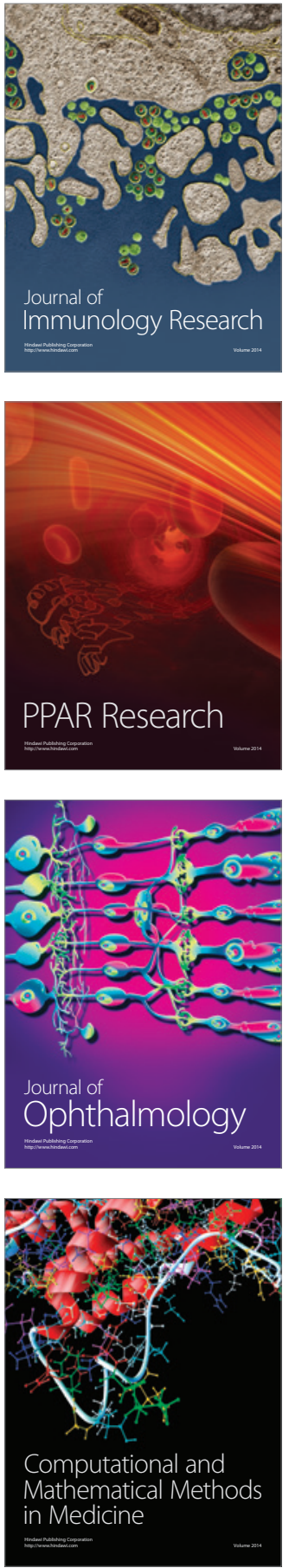

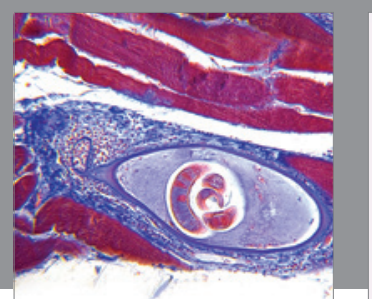

Gastroenterology Research and Practice

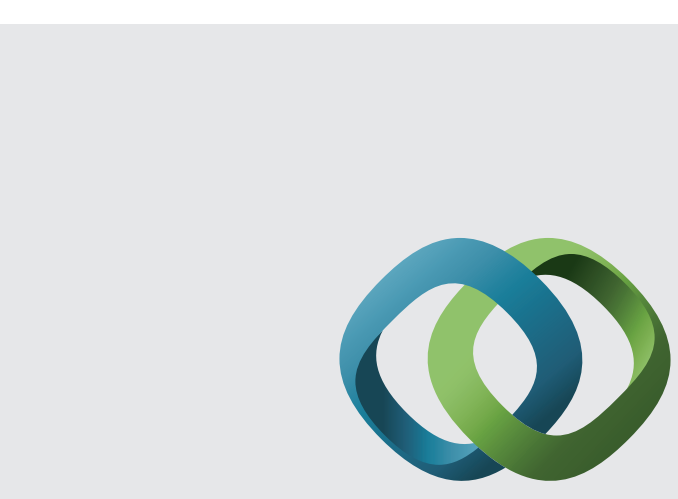

\section{Hindawi}

Submit your manuscripts at

http://www.hindawi.com
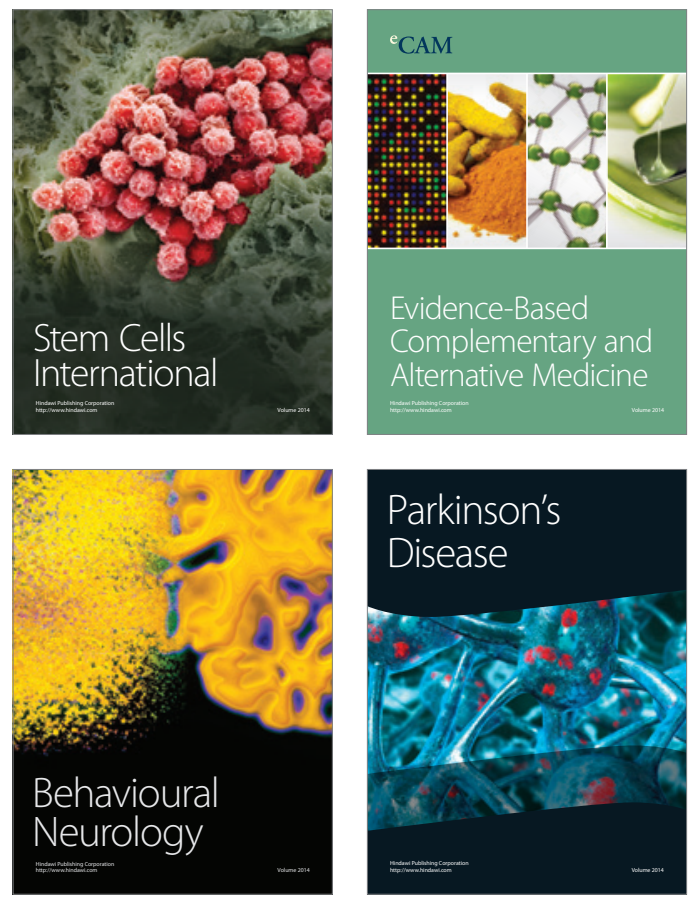
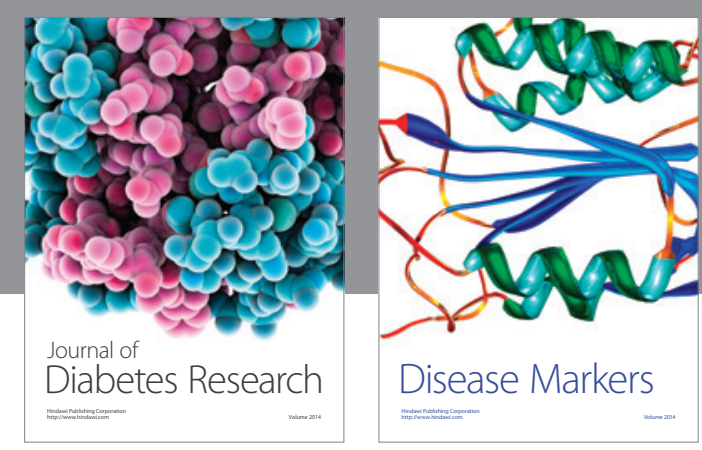

Disease Markers
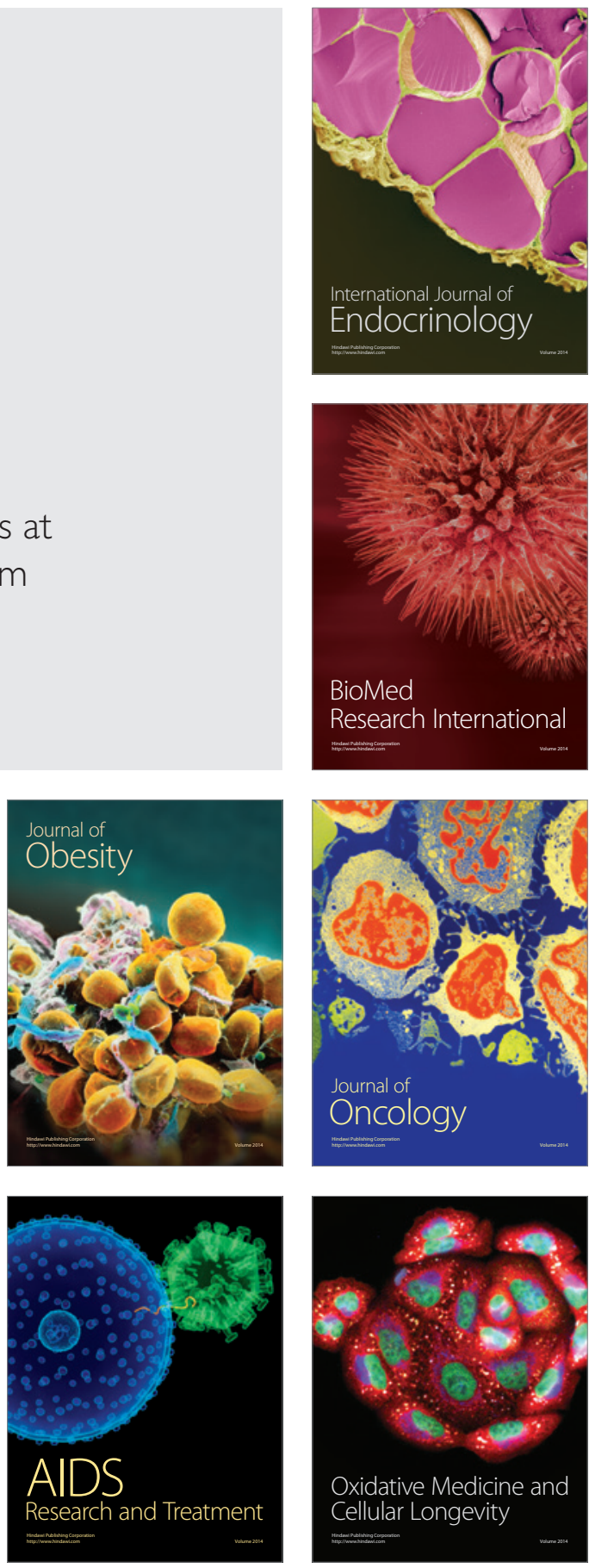